\title{
Çumra- Konya Bölgesindeki Yüksek Genlikli Gravite Anomalilerine Neden Olan Yapıların Araștırılması
}

\author{
Ezgi ERBEK ${ }^{* 1}$, M. Nuri DOLMAZ² \\ 1,2Süleyman Demirel Üniversitesi, Mühendislik Fakültesi, Jeofizik Mühendisliği Bölümü, 32260, Isparta, Türkiye
}

(Alınış / Received: 03.07.2019, Kabul / Accepted: 16.09.2019, Online Yayınlanma / Published Online: 30.12.2019)

Anahtar Kelimeler

Gravite anomalisi,

Tilt açısı,

Analitik sinyal
Özet: Konya ili sınırları içerisinde yer alan Çumra bölgesindeki yüksek gravite anomalilerinin nedeni olan yapılar spektral analiz ve yapı sınırı yöntemleri ile araştııılmıştır. Gravite verilerinin güç spektrumundan anomalilere neden olan yapıların ortalama derinlikleri hesaplanmıștır. Tilt açısı yöntemi ile ise bu yapıların sınırları ve üst yüzey derinlik değerleri belirlenmiștir. Gravite verilerine uygulanan analitik sinyal yönteminden yararlanılarak elde edilen tahmini taban derinlik dağılım haritasında derinlik değerlerinin $1.6 \mathrm{~km}$ ile $9.4 \mathrm{~km}$ arasında değiştiği görülmektedir.

\section{Investigation of The Structures Causing High Gravity Anomalies in Çumra-Konya Region}

\section{Keywords}

Gravity anomaly,

Tilt angle,

Analytic signal

\begin{abstract}
The structures which are the cause of high gravity anomalies in Cumra, Konya province were investigated by spectral analysis and boundary analysis methods. The average depths of the structures causing anomalies were calculated from the power spectrum of the gravity data. Tilt angle method was also used to determine the boundaries of these structures and the upper surface depth values were determined. Using the analytical signal method applied to the gravity data, the estimation basement depth distribution map was drawn and it was shown that the depth values ranged between $1.6 \mathrm{~km}$ and $9.4 \mathrm{~km}$.
\end{abstract}

\section{Giriş}

Çalışma alanını içine alan Çumra bölgesi Konya ili sınırları içerisinde yer almakta olup, havza yapısında ve ova olarak nitelendirilebilecek bir birikinti alanıdır [1]. Bölgedeki topografik yükseklik 975 m ile $2184 \mathrm{~m}$ arasında değișmektedir. Çalışma alanında ova kısımın deniz seviyesinden yüksekliği ortalama $1000 \mathrm{~m}$ civarında değişirken, batı kısımlara doğru yükseklik değerleri 2184 m' ye ulaşmaktadır (Şekil 1).

İç Anadolu'da yer alan çalışma alanı geçmiş dönemde bu bölgede yer alan Tetis Okyanusunun varlığından etkilenmiştir. Geç Paleozoyik dönemde doğmuş olan Tetis Okyanusu tektonik evrim sonucunda Tersiyer'de kapanmıştır. Son dönemdeki aşaması olan Neo-Tetis'de meydana gelen havzaların kalıntıları Anadolu'da kolayca gözlenebilmektedir [2].

Bölgede yer alan kayaçlar Paleozoyik- Kuvaterner yaş aralığında değişmekte olan çökelmiş jeolojik birimlerden oluşmaktadır. Bölgede yaygın olan
Mesozoyik birimler üzerinde ise mafik ve ultramafik kayaçlar yer almaktadır.

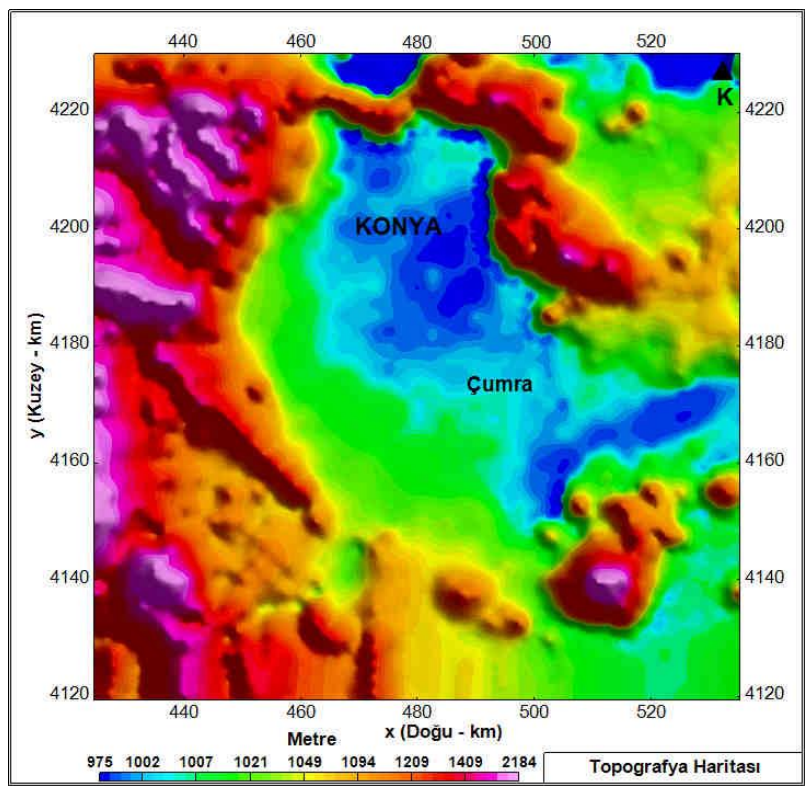

Şekil 1. Bölgenin topografik değişimini gösteren harita. 


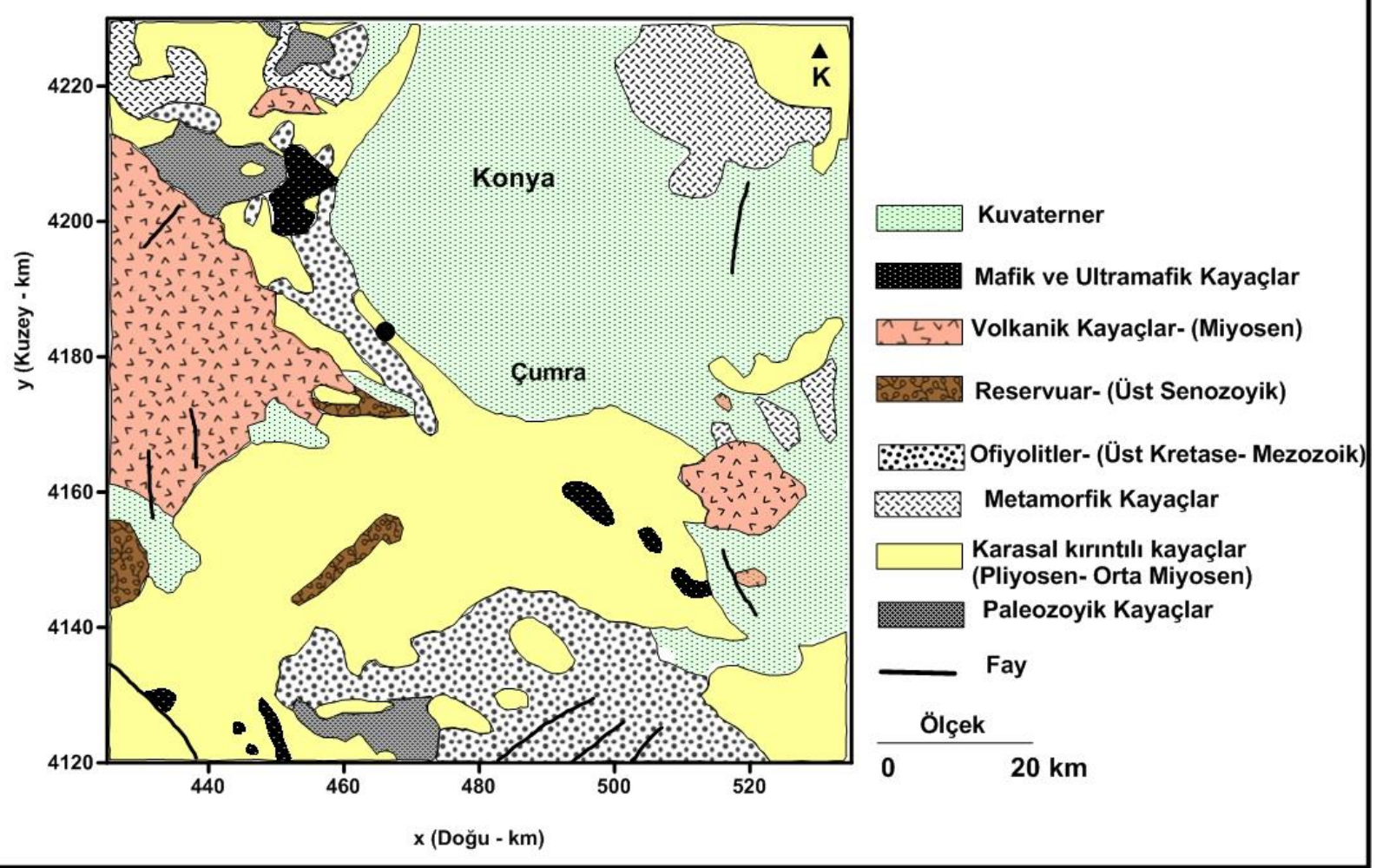

Şekil 2. Bölgenin sadeleștirilmiş jeoloji haritası [6 ve 8]' den değiștirilmiştir.

Özellikle Cumra ova bölgesinde Kuvaterner'e ait formasyonlar yaygın olarak görülmekte olup, Hakyemez vd. tarafindan Çumra, Okçu, Türkmencamili, Güvercinlik ve Karkın formasyonları olmak üzere beş grupta toplanmıştır [3]. Çumra formasyonu silttaşı ve kiltaşlarından oluşmakta ve Okçu, Türkmencamili ve Arıkören formasyonları yanal geçişlidir. Okçu formasyonu ise çapraz ve paralel tabakalı bol gastropod ve dreissensia kavkılı, kavkı kırıntılı az çimentolu çakıltaşı ve kum taşlarından oluşmuştur. Türkmencamili Formasyonu beyaz, krem rengi, açık gri ve gri renkli marn ve kumlu marnlardan oluşurken Güvercinlik Formasyonu koyu gri, koyu kahverengi ve siyahımsı kahverengi renklerde gevşek yapılı çamur tașlarından olușmaktadır [3,4]. Karkın formasyonu ise Sarımsı kahverengi ince kumtaşı, silttaşı ve kiltaşlarını içermektedir [5]. Bölgedeki ofiyolitler okyanus tabanı yayılmalarının ürünü olup bu durum Tetis okyanusun varlığının bir sonucu olarak değerlendirilmektedir. Bu çalışmada bölgenin jeolojik ve jeodinamik arka planı da göz önünde bulundurularak, Ateş ve Kearey [6]' in yaptığı çalışmadaki gravite verileri yeniden değerlendirilerek bölgede anomaliye neden olan yapılar, bunların sinırlarının ve yeraltı derinlik dağılımının belirlenmesi amaçlanmıştır.

\section{Materyal ve Yöntem}

\subsection{Materyal}

Bölgenin jeolojik, jeofizik, jeomorfolojik ve jeodinamik evrimi ile ilgili çok sayıda çalışma yapılmıştır. Koçyiğit [7] Konya (Ermenek) bölgesindeki ofiyolitik melanjları araștırmıștır. Bingöl [8] ise bölgede genel olarak kuvaterner depozitlerin varlığından bahsederken, mafik ve ultramafik kayaçların küçük mostralar verdiğini belirtmiştir. Konya ilindeki senozoyik kalk-alkalin volkanizması Temel vd. [9] tarafindan incelenmiştir. Hakyemez vd. [3] bölgeyi jeolojik açıdan detaylı olarak araştırmış ve bölgenin en yaşlı biriminin paleozoyik yaşlı mermerler olduğunu ifade etmişlerdir. Jeofizik açıdan Ateş ve Kearey [6] bölgeyi gravite ve manyetik verileri kullanarak değerlendirmiş, Albora vd. [10] hücresel sinir ağlarını kullanarak çalışma alanının yakın çevresinde tektonik modelleme yapmışlardır. Aydın ve İşseven [11] ise bölgedeki yüksek gravite anomali değerlerinin nedenini araştırmışlardır. Bu çalışma ile de bölgeye ait gravite verileri yeniden değerlendirilerek yüksek anomaliye neden olabilecek kaynakların konumları ve bölgede yer alan diğer gömülü yapıların sınırlarının belirlenmesi amaçlanmıştır.

Potansiyel alan yöntemlerinden olan gravite yöntemi yer altındaki yanal yönlü yoğunluk değişiminin neden olduğu gravite alanındaki değişimlerin ölçülmesine dayanmaktadır. Yöntem verilerin süzgeçlenmesi ve spektral analiz aşamalarının uygulanması, jeolojik birimlerin dokanak sınırlarının belirginleştirilmesi, veriden istenmeyen etkilerin uzaklaştırılması, sı $\breve{g}$ veya derin etkilerin kuvvetlendirilmesi, farklı yönelimlerdeki etkilerin ortaya çıkartılması gibi amaçlarla kullanılmaktadır. Çalışmada kullanılan gravite verileri yeniden sayısallaştırılarak analiz edilmeye hazır hale getirilmiștir. $2.5 \mathrm{~km}$ aralıklarla 
gridlenen gravite anomali haritası Şekil 3' te gösterilmektedir. Elde edilen anomali haritasında anomali değerleri -69.2 ile $13.2 \mathrm{mGal}$ aralığında değișmekte olup, Çumra bölgesi civarında KB-GD uzanımlı elipsoidal belirgin bir anomali verdiği görülmektedir.

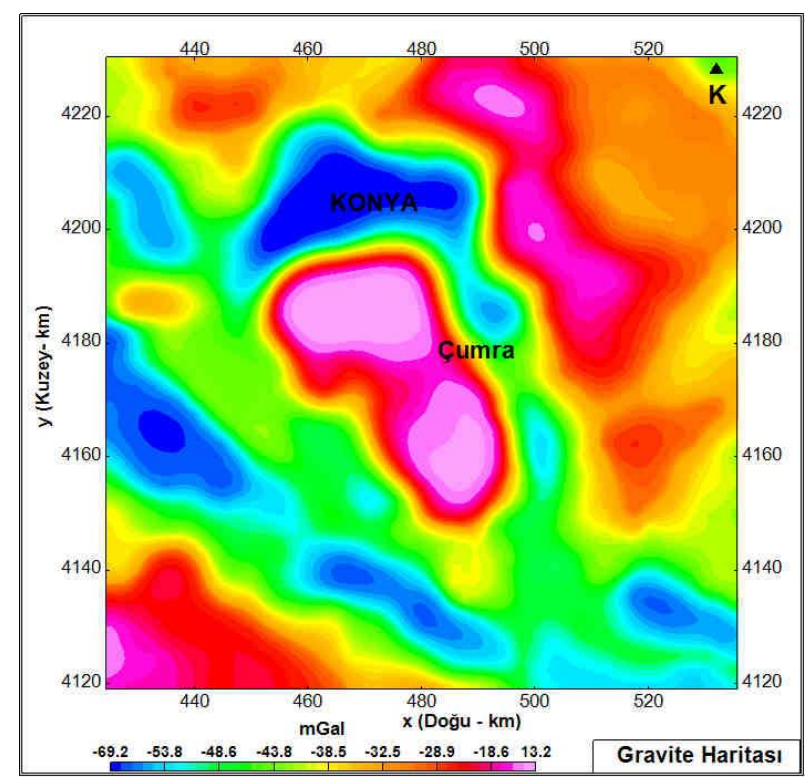

Şekil 3. Çalışma alanına ait Bouguer gravite anomali haritası.

\subsubsection{Rejyonal - Rezidüel Anomali Ayrımı}

Bouguer anomali verilerini oluşturan rejyonal ve rezidüel olmak üzere iki bileşen vardır. Rejyonal anomaliler derinlerdeki yapıların meydana getirdiği etkileri temsil etmete olup, uzun dalgaboylu ve düșük frekanslı verileri içermektedir. Rezidüel anomaliler ise yüzeye yakın sığ yapıların yarattı̆g etkilerdir. Bunlar kısa dalgaboylu ve yüksek frekanslı verileri içermektedir. Derin ve sığ yapıların derinliklerini belirlemek için verilere "Fourier Dönüşümü" olarak adlandırılan ișlem uygulanmıștır. Bu ișlem enerji spektrumlarını hesaplanmasinda kullanılır ve bunun sonucunda iki boyutlu güç spectrum eğrileri elde edilir. Bu eğrilerin eğimi ise sığ ve derin yapıların ortalama derinliklerini belirlememize imkan vermektedir. Bu çalışmada FFT uygulanarak Bouguer gravite anomalilerini meydana getiren yapıların ortalama derinlikleri belirlenmiştir (Şekil 4).

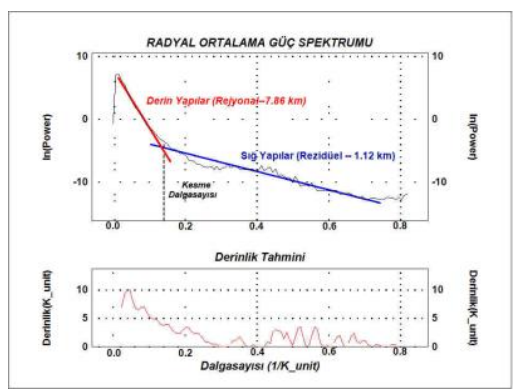

Şekil 4. Radyal ortalama güç spekturumundan elde edilen ortalama derinlik değerleri

Şekil 4' ten elde edilen kesme dalgasayısı (0.06 (1/K_unit) alçak geçişli filtremeleme işleminde kullanılarak rejyonal anomaliler elde edilmiștir (Şekil 5a). Belirlenen kesme dalga sayısının yüksek geçişli filtreleme işleminde kullanılmasıyla da bölgeye ait rezidüel anomaliler elde edilmiş ve anomali dağılım haritası Şekil 5b' de verilmiştir. Derin yapıların yarattığı KB-GD uzanımlı anomalilerin çalışma alanının merkezinde ve KD' sunda yer aldığı, sı yapılardan kaynaklanan etkilerin ise çalışma alanının hemen hemen her bölgesinde yer aldığı görülmüștür. Rejyonal anomaliler için elde edilen derinlik değerinin $(7.86 \mathrm{~km})$ alt kabukta yer alan yapılardan kaynaklanmış olabileceği gözlenmiştir. Rezidüel anomali haritasında ise orta kısımda yer alan pozitif anomalileri çevreleyen negatif anomalilerin varlığg bölgedeki farklı yoğunluklu yapıların yer aldığını göstermiştir.

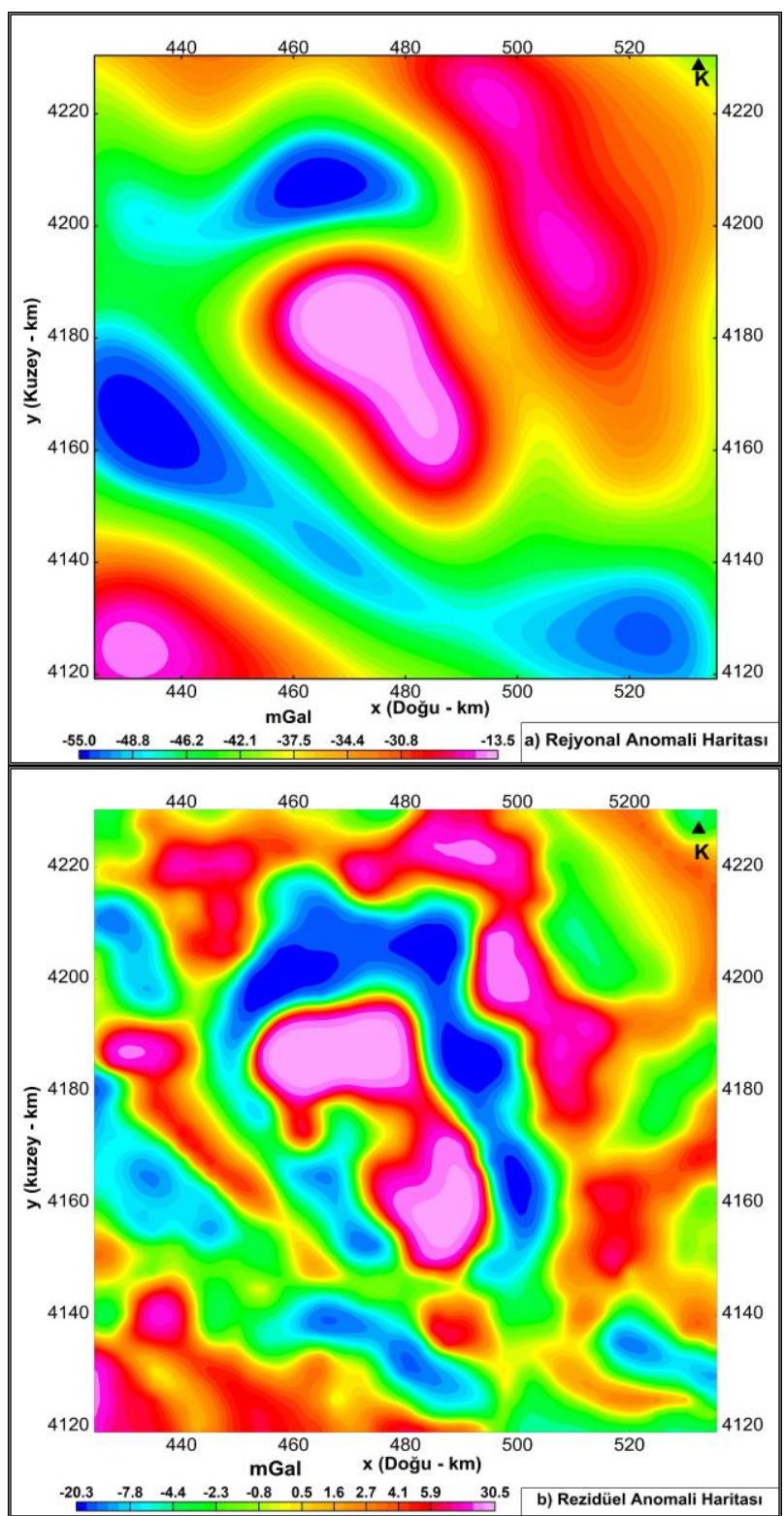

Şekil 5. a)Çalışma alanındaki derin yapılardan kaynaklanan etkileri gösteren rejyonal anomali haritası, b) Sı̆̆ yapılardan kaynaklanan etkileri gösteren rezidüel anomali haritası 


\subsection{Yöntem}

\subsubsection{Tilt Açısı Yöntemi}

Potansiyel alanın düşey türevinin, yatay türevine oranı olarak tanımlanan yöntem, uzanımları ve kontakt alanları tanımlamada, sığ yeraltı yapısının haritalandırılmasında, maden arama ve manyetik kaynakların sınırlarının belirlenmesi için kullanılmaktadır [12, 13]. Yöntemin Türkiye'deki uygulamalarından biri Akın vd. [14] tarafından Kırşehir paftası için gerçekleștirilmiștir. Çalıșmada tilt açısı yöntemi kullanılarak Geç Kretase yaşlı volkanik kayaçların yer altı konumlarının belirlenmesi amaçlanmıştır. Doğru vd. [15] ise tilt açısı yöntemi ile Batı Anadolu bölgesinin Bouguer gravite anomalilerini inceleyerek jeolojik yapı sınırlarını tanımlamışlardır. Yöntemin matematiksel bağıntısı 2 numaralı eşitlikte verilmiştir.

$$
\operatorname{TDX}=\sqrt{\left(\frac{\partial f}{\partial x}\right)^{2}+\left(\frac{\partial \mathrm{f}}{\partial \mathrm{y}}\right)^{2}}
$$

TDX, potansiyel alanın yatay türevini ifade ederken, $\frac{\partial f}{\partial x}, \frac{\partial f}{\partial y}$ toplam alanın $\mathrm{x}$ ve $\mathrm{y}$ yönündeki türevlerini göstermektir.

$$
\text { Tilt }=\arctan \left[\frac{\frac{\partial \mathrm{f}}{\partial \mathrm{z}}}{\mathrm{TDX}}\right]
$$

Bağıntaki $\frac{\partial \mathrm{f}}{\partial \mathrm{z}}$ toplam alanın $\mathrm{z}$ yönündeki türevini göstermektedir.

Tilt genlikleri, ark-trigonometrik fonksiyon olduğundan dolayı $\pm \pi / 2$ arasında değişirken, Salem vd. [16] $\pm \pi$ / 4 Radyan konturlar arasındaki yarı mesafenin dikey kontaktlar için kaynak derinliğinin tahminini sağladığını kanıtlamıştır. Genlikler, kaynak yapı üzerinde pozitif değerler gösterirler. Genliklerin negatif değerleri ise, kaynağın kenarına yakın veya kaynak bölgesinin dişında konumlanırlar. Özellikle sığ derinliklerde sıfır konturu yapıların sınırlarını temsil etmektedir.

\subsubsection{Analitik Sinyal ile Tahmini Taban Derinliği}

Analitik sinyal (AS) yöntemi ilk defa Nabighian $[17,18,19]$ tarafindan ortaya konmuş, daha sonra Roest vd. [20] tarafindan toplam manyetik alanın düşey gradientinden, ( $\mathrm{x}, \mathrm{y})$ konumundaki üç boyutlu analitik sinyalin genliklerinin kolayca elde edilebileceği gösterilmiştir. Bunu ;

$$
\mathrm{AS}=\sqrt{\left(\frac{d T}{d x}\right)^{2}+\left(\frac{d T}{d y}\right)^{2}+\left(\frac{d T}{d z}\right)^{2}}
$$

bağıntısı ile ifade etmişlerdir. T, toplam pontansiyel alanı, $\frac{d T}{d x}, \frac{d T}{d y}$ ve $\frac{d T}{d z}$ ise potansiyel alanın $x, y$ ve $z$ yönlerindeki türevlerini göstermektedir.
Yöntem potansiyel alan verilerinin yatay ve düşey türevlerini hesaplayarak, anomaliye neden olan yapıların sınırlarını tanımlamak için kullanılır. Ayrıca yöntemin yer manyetik alanından ve kaynak mıknatıslama yönlerinden bağımsız olması uygulamada büyük avantaj sağlamaktadır.

Ayrıca yöntem hesaplanan AS değerlerinin, AS' in düşey türevine (ASI) oranını kullanarak manyetik cisimlerin derinliğini tahmin etmeyi sağlar.

$$
\text { ASI }=\sqrt{\left(\frac{\partial \mathrm{fv}}{\partial \mathrm{x}}\right)^{2}+\left(\frac{\partial \mathrm{fv}}{\partial \mathrm{y}}\right)^{2}+\left(\frac{\partial \mathrm{fv}}{\partial \mathrm{z}}\right)^{2}}
$$

Bağıntıda, fv, potansiyel alanın düşey türevini, $\frac{\mathrm{dfv}}{\mathrm{dx}}, \frac{\mathrm{dfv}}{\mathrm{dy}}$ ve $\frac{\mathrm{dfv}}{\mathrm{dz}}$ ise potansiyel alanın düşey türevinin $\mathrm{x}$, y ve $\mathrm{z}$ yönlerindeki türevlerini göstermektedir.

Maksimum genlik;

$$
\mathrm{D}=\frac{\mathrm{AS}}{\mathrm{ASI}} \times \mathrm{N}
$$

D (m) manyetik gövdenin derinliğini göstermektedir. $\mathrm{N}$, manyetik kaynağın geometrisini temsil eder ve yapısal bir indeks olarak bilinir (küre için $\mathrm{N}=4$, boru için $\mathrm{N}=3$, ince dayk için $\mathrm{N}=2$, manyetik kontakt için $\mathrm{N}=1$ ).

\section{Bulgular}

Bölgedeki gravite anomalileri incelendiğinde Çumra çevresindeki KB-GD yönelimli elipsoidal pozitif anomalilerin varlığı dikkat çekmektedir. Bu duruma neden olabilecek etkinin Aydın ve İşseven [11] tarafından yapılan çalışmada yer altındaki $(4.84 \mathrm{~km}$ derinlikli) bir kütle fazlalığından kaynaklanabileceği belirtilmiş ve bu kütle fazlalığını 67.343 Gt olarak hesaplamışlardır. Topografik olarakta çevresine göre ( $2000 \mathrm{~m})$ düşük kotlu ( $1000 \mathrm{~m})$ bir alanda ÇumraKonya civarında yeraltında bulunan gömülü KB-GD uzanımlı yoğun bir materyalin beklenen düşük gravite anomalisi içerisinde çarpıcı şekilde yer alan pozitif bir anomaliye yol açmıştır.

Bu çalıșma ile bu yapının sınırlarını belirleyebilmek amacıyla uygulanan Tilt açısı yönteminden elde edilen harita Şekil 6' da verilmiştir. Harita üzerindeki 0 konturları yapıların sınırlarını temsil etmektedir. \pm ? $/ 4$ ( \pm 0.785$)$ konturları arasındaki yarı mesafeden Çumra civarındaki yapıdan seçilen noktalara (A1, A2, A3, A4, B1, B2, B3) ait yükselim sınırları için derinlik değerini hesaplamak mümkün olmuştur (Tablo 1).

Bölgeye ait oluşturulan analitik sinyal haritası Şekil 7' de verilmiştir. Potansiyel alanın yatay ve düşey türevlerinde dayanan yöntemde genlik değerlerinin yüksek olduğu yerler anomaliye sebep olan yapıya karşılık gelmektedir. Çumra çevresindeki pozitif gravite anomalilerine neden olan yapının sinırları harita üzerinde belirgin olarak görülmektedir. 


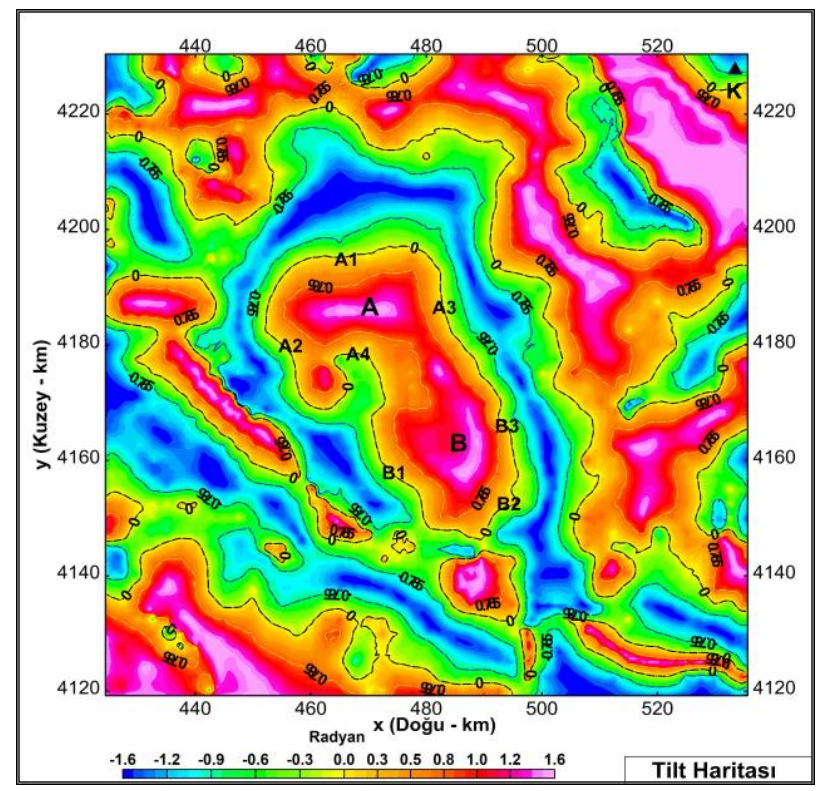

Şekil 6. Çalıșma alanına ait Tilt açısı haritası. Siyah kesikli çizgiler 0 konturunu gösterirken sarı ve mavi renkli çizgiler ise sırasıyla + ?/4 ve - ?/4 konturlarını göstermektedir.

Tablo 1. Tilt haritası üzerinde seçilen noktalar için hesaplanan derinlik değerleri

\begin{tabular}{cccc}
\hline Nokta & X (Doğu) & Y (Kuzey) & $\begin{array}{c}\text { Tilt Açısı Derinlik } \\
(\mathbf{k m}) \text { Değeri }\end{array}$ \\
\hline A1 & 465.411 & 4195.58 & 3.5 \\
A2 & 455.266 & 4180.01 & 2.5 \\
A3 & 482.91 & 4186.88 & 3.1 \\
A4 & 467.400 & 4178.72 & 8.1 \\
B1 & 473.368 & 4158.239 & 4 \\
B2 & 494.255 & 4152.27 & 5.4 \\
B3 & 493.459 & 4166.19 & 3.2 \\
\hline
\end{tabular}

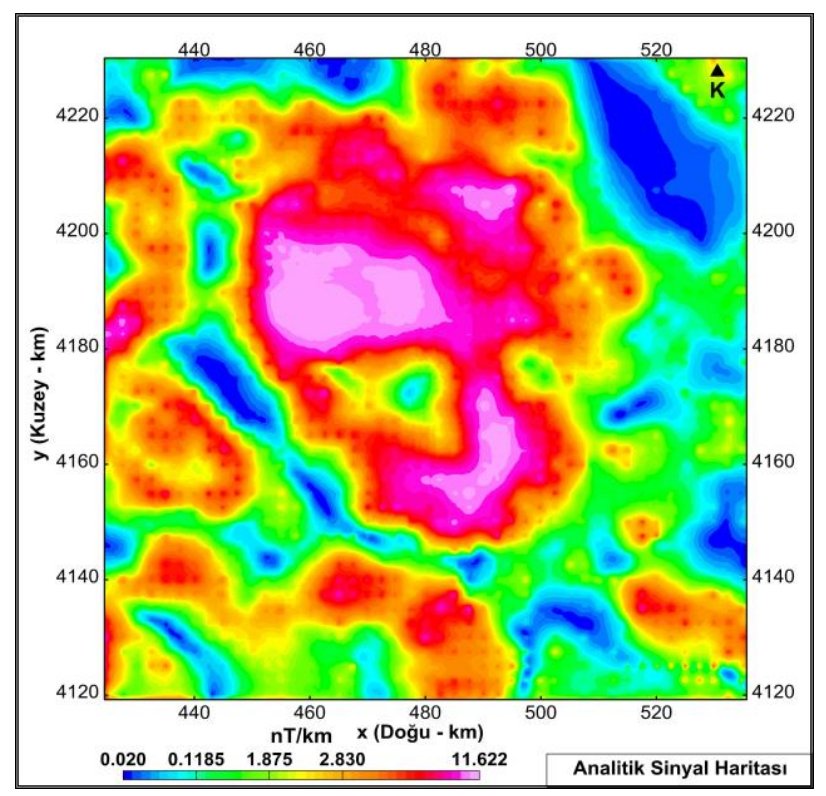

Şekil 7. Çumra ve çevresine ait analitik sinyal haritası

AS yönteminin kullanılmasıyla elde edilen tahmini taban yüzeyi üzerindeki derinlik dağılımı haritası Şekil 8' de verilmiştir. Buna göre bölgeye ait taban yüzeyinin üzerine kadar olan tahmini derinlik dağılımının $1.6 \mathrm{~km}$ ile $9.4 \mathrm{~km}$ aralığında değiştiği hesaplanmıștır. Hesaplanan sı̆̆ derinlik değerlerinin Çumra civarında yer aldğı gözlenmiștir. Ayrıca taban yüzeyi üzerindeki derinliğin maksimuma(derin) ulaştığı bölge Çumranın GB' sinda yer alan KB-GD uzanımlı alan olarak belirlenmiștir.

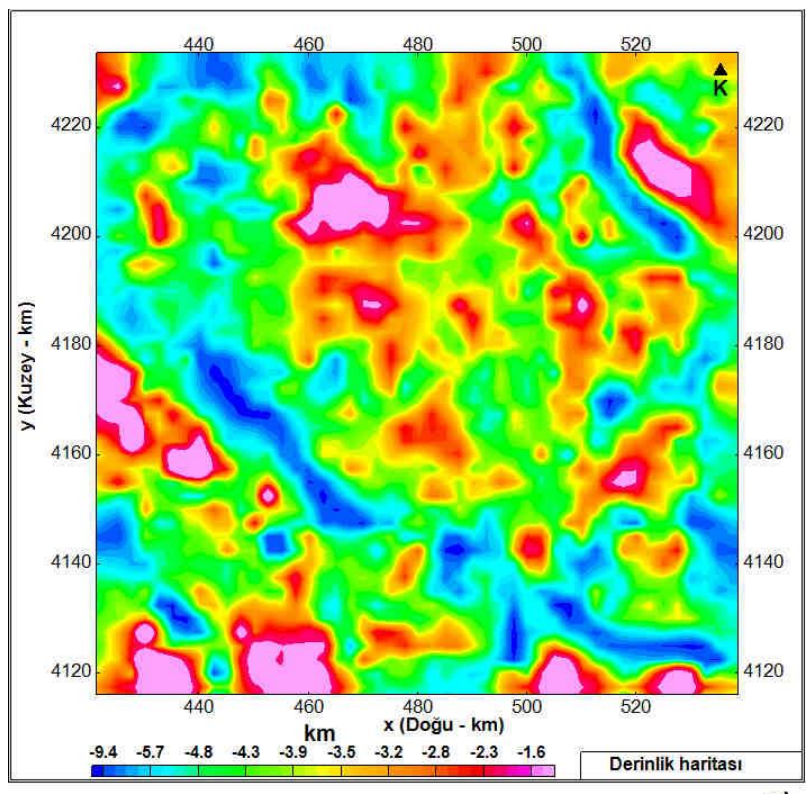

a)

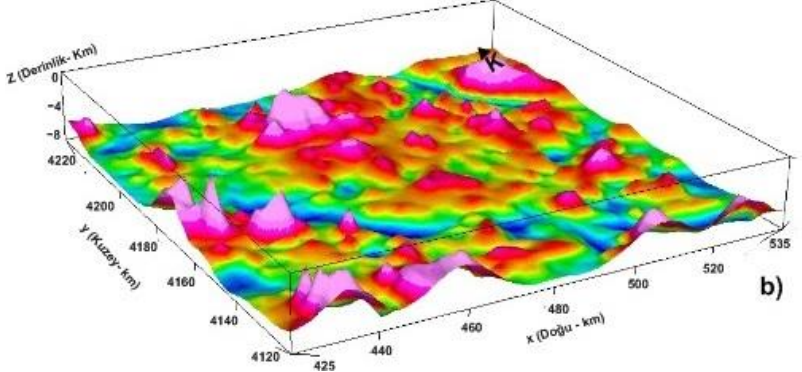

Şekil 8. a) Çalışma alanına ait taban yüzeyi üzerindeki derinlik dağılım haritası b) Tahmini taban yüzeyinin üzerindeki derinlik dağılımının 3B gösterimi.

\section{Tartıșma ve Sonuç}

$\mathrm{Bu}$ çalışmada yer altındaki yapıların yoğunluk, derinlik ve geometrilerine bağlı olarak değişen gravite yöntemine ait veriler yeniden sayısal hale getirilerek bölgedeki gömülü yapılara ait bilgiler ortaya konulmaya çalışılmıștır.

Çumra ve çevresi topografik olarak düz bir yapıda olmasına rağmen yüksek gravite anomalileri verdiği gözlenmiștir (Șekil 1 ve 3). Bölgeye ait gravite anomalilerine spektral analiz işlemleri uygulanarak rejyonal anomaliye neden olan kütlelerin ortalama derinliği $7.86 \mathrm{~km}$ bulunmuştur. Bölgedeki yüksek anomaliye neden olan yapıların Tetis Okyanusunun kapanması sırasında bölgeye yerleșen bir ofiyolit kütlesi olabileceği Aydın ve İşseven [11] tarafından belirtilmiştir. Bu bilgiler ıșığında etken yapıya ait sınırlar ve yapının üst derinlik değerleri seçilen noktalar için tilt açısı yöntemi uygulanarak hesaplanmıștır. Ayrıca Kuvaterner birimlerin altında yer alan bu etken yapının ve etrafının taban derinlik dağılımı hesaplanmıştır. Tilt açısı yöntemi kullanılarak yapının üst yüzeyden olan derinlik dağılımının yaklaşı olarak $2.5 \mathrm{~km}$ ile $8.2 \mathrm{~km}$ 
aralığında değiştiği belirlenmiştir. Buna göre bölgedeki en derin kismın ( $9.4 \mathrm{~km})$ Çumranın GB'sında yer alan bölgeye karşılık geldiği görülmüștür. AS haritasındaki maksimum değerler ise Çumra bölgesinde yer alan gömülü ofiliyotik kütlenin sınırlarının mıknatıslanma yönünden etkilenmeden tam konumunu işaret etmektedir. Güç spektrumu kullanılarak bölgenin geneli için anomaliye neden olan derin yapılara ait elde edilen derinlik $(\sim 7.1 \mathrm{~km})$ değerlerinin de tilt açısı yönteminden elde edilen değerler $(\sim 8 \mathrm{~km})$ ile uyum içerisinde olduğu görülmüştür.

\section{Kaynakça}

[1] Yiğitbaşığlu, H., 2001. Konya-Çumra Havzası'nda Arazi Kullanım Özellikleri ve Başlıca Sorunları, AÜ Türkiye Coğ.Arş. ve Uyg. Merk. Der. No:8, Ankara.

[2] Şengör, A. M. C., Yılmaz, Y., 1981. Tethyan Evolution of Turkey: A Plate Tectonic Approch. Tectonophysics, 75(3-4), 181-241.

[3] Hakyemez, H. Y., Elibol, E., Umut, M., Bakırhan, B., Kara, İ., Dağıstan, H., Metin, T., Erdoğan, N., 1992. Konya-Çumra-Akören Dolayının Jeolojisi. M.T.A. Rapor no: 42/24, 64, Ankara.

[4] Tuncer, B., 2011. Çumra (Konya) ilçesi'nin Beşeri ve Ekonomik Coğrafyası. Selçuk Üniversitesi, Eğitim Bilimleri Enstitüsü, Yüksek lisans Tezi, Konya.

[5] Tapur, T., 1998. Eski Konya gölü ve Çevresinin Fiziki Coğrafya Özellikleri. Selçuk Üniversitesi Sosyal Bilimler Enstitüsü, Yüksek Lisans Tezi, 87s, Konya.

[6] Ates, A., Kearey, P., 2000. Interpretation of gravity and aeromagnetic anomalies of the Konya Region, South Central Turkey. Journal of the Balkan, 3(3), 37-44.

[7] Kocyigit, A., 1976. The ophiolitic melange and other formations in the Karaman, Eremenek (Konya) region. Bulletin of the Geological Society of Turkey, 19, 103-116.

[8] Bingöl, E., 1989. 1:2 000000 scale geological map of Turkey, Publication of the Mineral Research and Exploration Company of Turkey.

[9] Temel, A., Gundogdu, M. N., Gourgard, A., 1998. Petrological and geochemical characteristic of Cenozoic high-K calcalkaline volcanism in Konya, central Anatolia, Turkey. Journal of
Volcanology and Geothermal Research, 85(1-4), 327-354.

[10] Aydın, N. G., İşseven, T., 2018. What is the reason for the high Bouguer gravity anomaly at Çumra, Konya (Central Anatolia)?, Turkish Journal of Earth Sciences, 27(4), 318-328.

[11] Albora, M.A., Ucan, O.N., Aydogan, D., 2007. Tectonic modeling of Konya-Beysehir Region (Turkey) using cellular neural networks. Annals of Geophysics, 50(5), 603-614.

[12] Mille,r H.G., Singh, V., 1994. Potential field tilt-a new concept for location of potential field sources. Journal of Applied Geophysics 32(2-3), $213-217$.

[13] Verduzco, B., Fairhead, J.D., Green, C.M., Mackenzie, C., 2004. The meter reader-new insights into magnetic derivatives for structural mapping. The Leading Edge, 23(2), 116 - 119.

[14] Akın, U., Şerifoğlu, B.I., Duru, M., 2011. Gravite ve manyetik yöntemlerde tilt açısı'nın kullanılması. MTA Dergisi, 143, 1-12.

[15] Doğru, F., Pamukçu, O., Özsöz, I., 2017. Application of tilt angle method to the Bouguer gravity data of Western Anatolia. Maden Tetkik ve Arama Dergisi, (155), 213-222.

[16] Salem, A., Williams, S., Fairhead, J., Ravat, D., Smith, R., 2007. Tilt-depth method: a simple depth estimation method using first-order magnetic derivatives. The Leading Edge, 26(12), 1502-1505.

[17] Nabighian, M. N., 1972. The analytic signal of two-dimensional magnetic bodies with polygonal cross-section: Its properties and use for automated anomaly interpretation. Geophysics, 37(3), 507-517.

[18] Nabighian, M.N. 1974. Additional comments on the analytic signal of two dimensional magnetic bodies with polygonal cross-section, Geophysics, 39(1), 85-92.

[19] Nabighian, M.N., 1984. Toward a three dimensional automatic interpretation of potential field data via generalized Hilbert transforms: Fundamental relations. Geophysics, 49(6), $780-786$.

[20] Roest, W.R., Verhoef, J., Pilkington, M., 1992. Magnetic interpretation using the 3-D analytic signal. Geophysics 57(1), 116-12. 